\title{
The COVID University Challenge: A Hazard Analysis of Critical Control Points Assessment of the Return of Students to Higher Education Establishments
}

\author{
Kelly L. Edmunds (iD, ${ }^{1}$ Laura Bowater, ${ }^{2}$ Julii Brainard (i), ${ }^{2}$ Jean-Charles de Coriolis, ${ }^{1}$ \\ Iain Lake, ${ }^{3}$ Rimsha R. Malik, ${ }^{2}$ Lorraine Newark, ${ }^{4}$ Neil Ward, ${ }^{5}$ Kay Yeoman, ${ }^{1}$ \\ and Paul R. Hunter ${ }^{2, *}$
}

The COVID-19 pandemic has disrupted economies and societies throughout the world since early 2020. Education is especially affected, with schools and universities widely closed for long periods. People under 25 years have the lowest risk of severe disease but their activities can be key to persistent ongoing community transmission. A challenge arose for how to provide education, including university level, without the activities of students increasing wider community SARS-CoV-2 infections. We used a Hazard Analysis of Critical Control Points (HACCP) framework to assess the risks associated with university student activity and recommend how to mitigate these risks. This tool appealed because it relies on multiagency collaboration and interdisciplinary expertise and yet is low cost, allowing rapid generation of evidence-based recommendations. We identified key critical control points associated with university student' activities, lifestyle, and interaction patterns both on-and-off campus. Unacceptable contact thresholds and the most up-to-date guidance were used to identify levels of risk for potential SARS-CoV-2 transmission, as well as recommendations based on existing research and emerging evidence for strategies that can reduce the risks of transmission. Employing the preventative measures we suggest can reduce the risks of SARS-CoV-2 transmission among and from university students. Reduction of infectious disease transmission in this demographic will reduce overall community transmission, lower demands on health services and reduce risk of harm to clinically vulnerable individuals while allowing vital education activity to continue. HACCP assessment proved a flexible tool for risk analysis in a specific setting in response to an emerging infectious disease threat. Systematic approaches to assessing hazards and risk critical control points (\#HACCP) enable robust strategies for protecting students and staff in HE settings during \#COVID19 pandemic.

KEY WORDS: COVID-19; education; HACCP; rapid response; SARS-CoV-2; university

${ }^{1}$ Centre for Ecology, Evolution and Conservation, School of Biological Sciences, University of East Anglia, Norwich, NR4 7TJ, UK.

${ }^{2}$ Norwich Medical School, University of East Anglia, Norwich, NR4 7TJ, UK.

${ }^{3}$ School of Environmental Sciences, University of East Anglia, Norwich, NR4 7TJ, UK.

${ }^{4}$ Learning and Teaching Service, University of East Anglia, Norwich, NR4 7TJ, UK.

\section{INTRODUCTION}

Emerging infectious diseases present substantial threats to global health (Jones et al., 2008). The current outbreak of SARS-CoV-2 that causes

${ }^{5}$ Vice Chancellor's Office, University of East Anglia, Norwich, NR4 7TJ, UK.

*Address correspondence to Paul Hunter, Norwich Medical School, University of East Anglia, Norwich, NR4 7TJ, UK; paul.hunter@uea.ac.uk 
COVID-19 disease caught countries unaware and presented unprecedented challenges. As of April 6, 2021 the pandemic is linked to over 130 million confirmed cases and 2.84 million deaths (as at04/06/21; WHO, 2020a). The long-term socioeconomic harms of the pandemic are forecast with alarming numbers across multiple sectors including employment, global GDP, national debt, and public service provision (World Bank, 2020). It is people under 25 years that are least in danger from the virus clinically (Russell et al., 2020), but this group arguably will shoulder the greatest long-term burden that result from for the current efforts to control the virus in-order to reduce societal harms. These dis-benefits/disadvantages include reduced education, reduced employment opportunities, and living longer with degraded quality public services that in turn includes education that is likely to be highly resource-restricted in the near future (Maher, Hoang, \& Hindery, 2020).

Early analyses suggests that closures of educational facilities had helped to reduce the outbreak in individual countries (Davies, Kucharski, Eggo, Gimma, \& Edmunds, 2020; Hunter, Colon-Gonzalez, Brainard, \& Rushton, 2020; Li et al., 2020), through a variety of mechanisms. Although it remains unclear exactly how likely young children are to be infected by or transmit SARS-CoV-2, educational establishments contain adults that are interacting, collaborating, and mixing. Also, young children are typically escorted to schools by adults who encounter other adults en route. Secondary and tertiary students often travel to school using public transport interacting highly with both each other and other adults en route and on site.

The prospect of shutting down educational facilities for long durations during the pandemic was not viable because the resultant unacceptable harm to both individuals and the wider economy was highly likely. For the age range 18-24 there was an additional consideration: a University College London survey found that loneliness during early lockdown was common in the age demographic (Leavey, Eastaugh, \& Kane, 2020), an age when counts of social contacts normally peak rather than contract (Mossong et al., 2008). Full time home-study could increase loneliness and was often physically hampered by practical problems: many young adults live in rented accommodation without adequate quiet and dedicated space at home to study effectively (Leavey et al., 2020). Good internet access from home, or access to a Personal Computer/laptop, could also not be assured for all even in high income countries (Auxier \& Anderson, 2020; Wakefield, 2020). For individuals, a decision to suspend education/training and enter the labor market temporarily was not appealing as unemployment rates rose sharply (CTV News, 2020; Ergocun, 2020; Heath, 2020). For those students starting the new academic year in September 2020, approximately a third would have been enrolling in their first year of university study, which would bring with it additional unknowns.

A societal problem with the prospect of suspending university education for an uncertain but long duration was the medium-long term effects on professional training. Most high-income countries recruit each year large numbers of newly trained graduates into a wide range of key worker professions, including nursing, medicine, allied health professions, social care, engineering, science, and teaching. Suspending university education would increase existing shortages of essential degree-qualified workers across multiple sectors (Garcia \& Weiss, 2019; Gilroy, 2019). Replacement recruitment of professionals from other parts of the world was unlikely given long training times required and pandemic disruption of education everywhere. It was also apparent that some universities faced severe financial crisis if students did not return to conventional tertiary education provision environment (Drayton \& Waltmann, 2020); contraction of the tertiary education sector is not desirable as pandemic conditions demonstrated the value of degree trained professionals for response and infectious disease control.

Ensuring the continuation of tertiary education during the pandemic was imperative. Some degree courses can be effectively delivered in a tele-learning (online) format, but many courses still depend on practical work in laboratories, using university equipment as well as placement opportunities in external facilities that deliver in-person training. This reliance on specific facilities and types of training is especially true for vocational courses such as medicine, nursing, midwifery, and physiotherapy is a challenge faced by our own institution which normally graduates hundreds of qualified health professionals each year. We were also aware that many nonhealth care students in our community, studying entirely online university degrees, lived on or near to campus and might still rely on other types of community locations (field work) or university facilities (such as the library or laboratories). 
Therefore, the aim of this research was to identify the critical control points among the usual and necessary activities of university students-points where the risks of transmission were greatest but could also be mitigated and reduced-to make recommendations for mitigating these risks. The approach for this research involved the use of the Hazard Analysis of Critical Control Points (Ha) framework; a low-cost tool for rapid assessment, that is simple for stakeholders to engage in, encourages multiagency collaboration and interdisciplinary expertise whilst generating evidence-based recommendations (Edmunds, Hunter, Few, \& Bell, 2013). HACCP assessments originated in risk management of food production systems, but have been increasingly used to assess risks related to an emerging health threats and infectious diseases (see Edmunds et al., 2013, 2016).

We applied the HACCP approach to the activities of university students and propose this method as a potential tool to generate recommendations when dealing with a rapidly evolving infectious disease outbreak. Here we provide a demonstration for how this rapid assessment tool can be used as part of a response toolkit for novel infectious disease outbreaks and describe the application of the HACCP framework to a Higher Education setting. We identify behaviors and practices linked to typical student activities, which are likely to present risks for the transmission, both direct and indirect, of SARS-CoV-2. HACCP assessments are potentially powerful methods that can be used as rapid response tools in specific settings during emerging infectious disease outbreaks, as a precursor to more time-consuming and costly quantitative data collection, biomedical testing, and clinical studies in specific settings.

\section{METHODS}

To complete our assessment of the risks of SARS-CoV-2 transmission during the return of students to UK university settings during the COVID-19 pandemic, we followed the first three HACCP principles as follows:

(1) To outline the key "risk" stages in the system being investigated,

(2) To identify the critical control points (CCPs) within the system being investigated and,

(3) To develop CCPs and recommendations to control the identified hazards (as used in pre- vious studies into EIDs; Edmunds et al., 2013, 2016).

The first stage of the process involved a series of virtual workshops and meetings amongst the HACCP team; all of whom were based at the higher education setting of the University of East Anglia (UEA) in Norwich, UK; a campus-based university with a student population of 17,429 in 2019/20 (of which 8,067 [46.3\%] were new starters) (UEA, 2020). The HACCP team includes experts in the fields of microbiology, infectious diseases, EIDs, public health, environmental health, science communication, student safety, and student administrative services. The first workshop and subsequent follow-up discussions led to the creation of early versions of six flowcharts which consider different scenarios for student interactions on campus. These were (i) on-campus teaching; (ii) off-campus teaching; (iii) living on campus; (iv) living off-campus; (v) nonteaching on-campus activities, and (vi) social activities. Following further consultation, the flowcharts were then critically analyzed by the team and finalized, simplified versions produced. A hazard was considered to be a process that could take place within a higher education university setting that would provide the opportunity, at an unacceptable level of risk, for the transmission of SARS-CoV-2 to another person. Taking into account the likelihood of a situation occurring and the likelihood of SARS-CoV-2 transmission being able to occur within that situation, the hazards were then grouped into high, medium, and low-risk categories. We generated recommendations for high-risk critical control points. The focus on high-risk CCPs is because our key objective was to make a set of recommendations that would do most to reduce transmission of SARS CoV-2 without being too onerous and likely to be followed. In concurrent circumstances (late 2020), an eradication strategy was not feasible in the UK. However, effective suppression of wide transmission to strongly limit harms from COVID19 was stated in government policy and supported by most institutions and public experts (BBC, 2020; UK Government, 2020a). Therefore, in this HACCP exercise, we focused our recommendations on only situations which generate the majority of transmissions ("high risk"), but this HACCP exercise did not address situations where likelihood of transmission was low or medium. Our intention was to seek recommendations to keep the prevalence of infections at low and manageable levels in both universities and the wider communities they engage with. This would 
have maximum impact while risk of transmission is high but a move to focus on lower risk transmission activities could be part of further HACCP steps if a near-elimination strategy for community COVID-19 control became viable.

Following validation of the flowchart, the same team of experts focused on all of the high-risk hazards and determined appropriate critical control points (CCPs). A CCP is a point at which there is the opportunity to control, prevent, or eliminate the risks for pathogen transmission. Critical limits were then set for each of the CCPs identified. These critical limits are thresholds used as preventative measures to control the hazards within the system. The outputs of each of these three principles were cross-referenced with the existing literature on SARS-CoV-2 epidemiology, prevention, and control.

\section{RESULTS}

\subsection{Hazard Analysis}

Our HACCP assessment of the risks of SARSCoV-2 transmission for students in UK university settings during the COVID-19 pandemic identified high-risk potentially hazardous practices linked to social interactions, teaching sessions, and day-to-day on-campus activities (Supporting Information Table I). Primary concerns were shared use of social spaces such as sports changing rooms, prayer facilities, study facilities including teaching rooms, and rooms for the examination of patients for those students on medical and health science courses. When considering the sharing of student residences (both on and off campus), all those ordinarily living within the student residence were considered to come from the same household. Thus, social distancing and other protective measures such as the use of face coverings during interactions between them was not deemed necessary, unless one or more members of the household were presenting with symptoms of COVID-19 or had received a positive test result in the previous 14 days. All other activities and practices linked to students at higher education establishments were deemed to present a medium or low level of risk for the transmission of SARS CoV-2.

\subsection{Critical Control Points and Critical Limits}

In total, 22 high-risk CCPs were identified by this HACCP assessment. Each CCP is a point at which there is an opportunity to adopt measures to reduce the risks of transmission of SARS CoV-2 during the return of students to UK university settings. Following extensive consultation and cross-referencing with the existing literature, critical limits were then proposed for each high-risk CCP. In many cases, multiple recommendations were made for each CCP (Supporting Information Table I).

Several of the critical limits suggested include fundamental infection control practices for coronaviruses, namely the correct and proper use of face coverings, employing appropriate hand hygiene measures, and adopting appropriate social distancing measures, such as concurrently recommended physical distancing in the UK at a minimum of $1 \mathrm{~m}+$.

\section{DISCUSSION}

The HACCP framework allows for a rapid identification of the risks associated to a specific setting and evolving disease outbreak, in this case SARSCoV-2 transmission to, from and between university students. The COVID-19 pandemic has highly disrupted education at all levels. It seems clear that shutting educational facilities can reduce community prevalence of SARS-CoV-2 but the harms long-term closure would cause to individuals and wider society are unacceptable. Therefore, strategies need to be found that enable most education delivery to continue, including forms of training that require physical use of education facilities.

No degree of pandemic preparedness can ever be fully comprehensive. This is because the nature of microbial contagions is that they tend to have unique features specific to the pathogenicity of the disease. A unique feature of the SARS-CoV-2 pandemic is that severe infection is uncommon within the key demographic groups of children and young people (Brookman et al., 2021). However, there are many aspects of effective COVID-19 control that require tremendous disruptions to the lives of young people. Our HACCP assessment used a structured methodology to evaluate opportunities for mitigating risks of SARS-CoV2 transmission associated with usual activities of university students, in an effort to facilitate their continued and essential education and training.

It seems clear that a proportion of SARS-CoV-2 transmission is from infected persons who lack symptoms: either presymptomatic and probably completely asymptomatic infections (Gandhi, Yokoe, \& Havlir, 2020). The diversity of symptoms experienced is also large: COVID-19 is not simply an 
influenza-like illness with fever and cough as diagnostic symptoms (Sahoo, Jhunjhunwala, \& Jolly, 2020). This situation presents unique challenges in terms of identifying cases and preventing them from passing the virus on. In peak prevalence periods, infection control relies on assuming that oneself and all other persons are potentially infected and therefore the only way to limit spread is through dramatically decreased contact with all other persons-even those with no contact or recent symptom history (Menon, 2020).

Our results feature recurring mitigation measures due to understanding of common disease transmission pathways and dynamics. Physical distancing from others (at least $2 \mathrm{~m}$ ) is believed to be especially effective because the predominant transmission pathway is via saliva droplets and possibly aerosols (WHO, 2020b). There is mixed quality evidence about the utility of wearing masks or face coverings to prevent COVID-19 in individuals. A recent systematic review (Brainard, Jones, Lake, Hooper, \& Hunter, 2020) concluded that wearing masks had some benefit for reducing transmission when either or both infected and uninfected persons wore the mask. However, we did not consider mask wearing provided a guarantee of protection and was certainly not a stand-alone alternative to other social distancing measures. The overall benefits of requiring populations to wear face coverings on wider community prevalence and subsequent mortality from COVID19 are thought to be definite but "limited" in impact (Cowling \& Leung 2020).

By focusing on high-risk contexts, we provide recommendations that would have maximum effect in keeping both the university and wider community prevalence of the infections at relatively low and thus manageable levels.

High ventilation rates and outdoor settings are believed to be linked to lower risk of transmission (Bhagat, Wykes, Dalziel, \& Linden, 2020). Good hand hygiene is basic infection control practice, as are measures to reduce the chances of fomite transmission (by sanitizing any potentially shared objects) (Goldman, 2020; Mondelli, Colaneri, Seminari, Baldanti, \& Bruno, 2020). How to follow these principles in avoiding infection depends somewhat on setting and activity, such as meetings, religious worship, returns from family visits, queuing, interactions with household members, and so on. We acknowledge in Supporting Information Table I that guidance and understanding of best infection control practices regarding COVID-19 are still emerging and recom- mend that students consult local guidance as it is published. Each transmission opportunity can be minimized or even eliminated through careful implementation of the critical limits outlined in Supporting Information Table I.

At our own university, the response to COVID19 has had three main components, covering communications, social distancing, and testing and monitoring. Regular communications were sent to all students about COVID-19 safety measures and the University's expectations around responsible behavior. These were reinforced by enhanced security and monitoring of students on-campus, in accommodation and in other social settings, to discourage and prevent social gatherings that span households. Hand sanitizer and associated signage provided in teaching rooms and at key points in communal areas helped maintain a visible reminder of COVID-19 risk. To help ensure adequate distancing, one-way systems for navigating corridors within buildings and the narrower pathways outside on campus were introduced. In addition, a precautionary approach to $2 \mathrm{~m}$ distancing in teaching rooms was pursued, based on shoulder-to-shoulder measurement, and assuming some potential movement of torsos while sitting at desks (teaching room capacities were between 10 and $20 \%$ of normal).

At the start of autumn term, the University introduced an asymptomatic testing scheme in partnership with the Earlham Institute, a genomics research laboratory also located on the Norwich Research Park (Gillam et al., 2020). The "Norwich Testing Initiative" had capacity to analyze 500 PCR tests per day. All members of the university community (students and staff) who regularly visited campus or lived there were encouraged to get tested. Positive case students and their households were isolated for 10 days with nonsymptomatic, nonpositive housemates isolating for 14 days, with regular welfare support for those living off campus. There was daily monitoring of case numbers and patterns by University Safety Services and members of the University's Executive Team, through a daily Major Operations Group meeting, to review trends and patterns and adjust the University's response as necessary.

After students arrived back at UEA at the start of autumn term, the number of actively positive student cases being managed peaked at just 69 after 3 weeks, but fell to below 25 by week 6 . There were just two cases that tested positive in the previous 10 days, by December 9th. Of 360 cases in total detected over the first 11-weeks of monitoring, just three were 
members of staff involved in teaching. This suggests that the transmission reduction measures taken to prevent spread in teaching spaces were successful.

This article presents a demonstration of how the HACCP framework can be used as an infection mitigating tool to be used as part of the response to an emerging infectious disease outbreak. Assessing the success of the HACCP framework for this setting at this time is a challenging task that would require expanding its' application across multiple university settings, using different infection control strategies. For such a complex, widespread and dynamic situation as presented by COVID-19, this would also require the development of novel, sophisticated, and real-time costly monitoring tools, which would need constant review and modification to have any chance of being able to accurately evaluate such a rapidly changing situation.

\section{CONCLUSIONS}

The COVID pandemic has delivered many epidemiological lessons and revealed numerous shortcomings in both local and international responses to emerging infectious diseases (EID). In the early stages of responding to an EID outbreak, the use of a response tool such as the HACCP framework allows for the rapid identification of risks and hazardous behaviors. Better risk reduction strategies can be generated after implementation of in-depth epidemiological studies, but such studies can take months or years to complete and produce results and recommendations. In contrast, the HACCP framework can be implemented fairly quickly using diverse informants and stakeholders. The long-term consequences of the emergence of COVID-19 are proving difficult to predict, but we can still do much to limit pandemic harms. There is considerable merit in rapid responses methods to minimize harms linked to future disease outbreaks.

\section{ACKNOWLEDGMENTS}

Professors Hunter and Lake as well as Dr. Brainard to the National Institute for Health Research Health Protection Research Unit (NIHR HPRU) in Emergency Preparedness and Response at King's College London in partnership with Public Health England (PHE) and the University of East Anglia. The views expressed are those of the authors and not necessarily those of the NHS, the NIHR, UEA, the Department of Health or Public Health
England. The authors are grateful to Jim Hunter of the University of East Anglia Safety Services staff for his valuable input and thank all those who have provided comment at any stage of the HACCP assessment or on this manuscript. As this study did not directly involve human subjects or data about individuals, ethical approval was not required.

\section{REFERENCES}

Auxier, B., \& Anderson, M. (2020, March 16). As schools close due to the coronavirus, some U.S. students face a digital 'homework gap'. Pew Research Center. Retrieved from https:// www.pewresearch.org/fact-tank/2020/03/16/as-schools-closedue-to-the-coronavirus-some-u-s-students-face-a-digitalhomework-gap/

BBC. (2020, October 12). Coronavirus: WHO head calls herd immunity approach 'immoral'. $B B C$. Retrieved from https://www. bbc.co.uk/news/world-54518286

Bhagat, R. K., Wykes, M. D., Dalziel, S. B., \& Linden, P. F. (2020). Effects of ventilation on the indoor spread of COVID19. Journal of Fluid Mechanics, 903, F1, https://doi.org/10.1017/ jfm.2020.720.

Brainard, J. S., Jones, N., Lake, I., Hooper, L., \& Hunter, P. (2020). Community use of facemasks and similar barriers to prevent respiratory illness such as COVID-19: A rapid scoping review. Eurosurveillance, 25(49). https://doi.org/10.2807/1560-7917.ES. 2020.25.49.2000725

Brookman, S., Cook, J., Zucherman, M., Broughton, S., Harman, K., \& Gupta, A. (2021). Effect of the new SARS-CoV2 variant B.1.1.7 on children and young people. The Lancet Child \& Adolescent Health, 5(4), E9-E10. https://doi.org/10. 1016/S2352-4642(21)00030-4

Centers for Disease Control and Prevention. (2020a). Keeping the workplace safe. Retrieved from https: //www.cdc.gov/coronavirus/2019-ncov/downloads/ workplace-school-and-home-guidance.pdf

Centers for Disease Control and Prevention. (2020b). Handwashing: Clean hands save lives. When and how to wash your hands. Retrieved from https://www.cdc.gov/handwashing/ when-how-handwashing.html

Centers for Disease Control and Prevention. (2020c). Cleaning and disinfection for households. Retrieved from https: //www.cdc.gov/coronavirus/2019-ncov/prevent-getting-sick/ cleaning-disinfection.html

Cowling, B. J., \& Leung, G. M. (2020). Face masks and COVID19: Don't let perfect be the enemy of good. Eurosurveillance, 25(49). Retrieved from https://doi.org/10.2807/1560-7917. ES.2020.25.49.2001998

CTV News. (2020, May 08). Canada's jobless rate soars to 13 per cent in April. CTV News. Retrieved from https://www.ctvnews.ca/business/canada-s-jobless-rate-soarsto-13-per-cent-in-april-1.4930397

Davies, N. G., Kucharski, A. J., Eggo, R. M., Gimma, A., \& Edmunds, W. J. (2020) Effects of non-pharmaceutical interventions on COVID-19 cases, deaths, and demand for hospital services in the UK: A modelling study. The Lancet Public Health, 5(7), E375-E385, Retrieved from https://doi.org/10. 1016/S2468-S2667(20)30133-X

Drayton, E., \& Waltmann, B. (2020, July 06). Will universities need a bailout to survive the COVID-19 crisis? Institute for Fiscal Studies. Retrieved from https://www.ifs.org.uk/publications/ 14919

Edmunds, K. L., Hunter, P. R., Few, R., \& Bell, D. J. (2013). Hazard analysis of critical control points assessment as a tool to 
respond to emerging infectious disease outbreaks. PLOS ONE, 8(8), e72279. https://doi.org/10.1371/journal.pone.0072279.

Edmunds, K. L., Abd Elrahman, S., Bell, D. J., Brainard, J., Dervisevic, S., Fedha, T. P., ... Hunter, P. (2016). Dealing with Ebolainfected waste: A Hazard Analysis of Critical Control Points for reducing the risks to public health. Bulletin of the World Health Organization, 94, 424-432. Retrieved from https://doi. org/10.2471/BLT.15.163931

Ergocun, G. (2020, October 01). EU unemployment in August rises to 7.4\%. Anadolu Agency. Retrieved from https://www.aa. com.tr/en/economy/eu-unemployment-in-august-rises-to-74-/ 1992138

European Centre for Disease Prevention and Control. (2020). Contact tracing: Public health management of person, including healthcare workers, having had contact with COVID-19 cases in the European Union. Stockholm, Sweden: ECD. Retrieved from https://www.ecdc.europa.eu/sites/default/files/ documents/covid-19-public-health-management-contactnovel-coronavirus-cases-EU.pdf

Gandhi, M., Yokoe, D. S., \& Havlir, D. V. (2020). Asymptomatic transmission, the Achilles' heel of current strategies to control COVID-19. New England Journal of Medicine, 382, 21582160.Retrieved from https://doi.org/10.1056/NEJMe2009758

Garcia, E., \& Weiss, E. (2019). The teacher shortage is real, large and growing, and worse than we thought. Report. Economic Policy Institute. 26 March 2019, available at Retrieved from https://www.epi.org/publication/the-teacher-shortage-is-reallarge-and-growing-and-worse-than-we-thought-the-firstreport-in-the-perfect-storm-in-the-teacher-labor-marketseries/

Gillam, T. B., Cole, J., Gharbi, K., Angiolini, E., Barker, T., Bickerton, P., ... Steel, N. (2020). Norwich COVID-19 testing initiative pilot: Evaluating the feasibility of asymptomatic testing on a university campus. Journal of Public Health, 43(1), 82-88. https://doi.org/10.1093/pubmed/fdaa194

Gilroy, R. (2019, November 28). NHS workforce being 'hollowed out' by registered nurse shortages. Nursing Times. Retrieved from https://www.nursingtimes.net/news/workforce/nhsworkforce-being-hollowed-out-by-registered-nurseshortages-28-11-2019/

Global Heat Health Information Network, (2020). Do air conditioning and ventilation systems increase the risk of virus transmission? If so, how can this be managed? Retrieved from https: //www.ghhin.org/heat-and-covid-19/ac-and-ventilation

Goldman, E. (2020). Exaggerated risk of transmission of COVID19 by fomites. Lancet Infectious Diseases, 20(8), 892-893. https: //doi.org/10.1016/S1473-3099(20)30561-2

Heath, M. (2020, June 18). Australian unemployment soars on record back-to-back job losses. Bloomberg. Retrieved from https://www.bloomberg.com/news/articles/2020-0618/australian-unemployment-jumps-to-7-1-in-may-currencydeclines

Hunter, P. R., Colon-Gonzalez, F., Brainard, J. S., \& Rushton, S. (2020). Impact of non-pharmaceutical interventions against COVID-19 in Europe: A quasi-experimental study. Eurosurveillance, In Press. Retrieved from https://doi.org/10/1101/ 2020.05.01.20088260

Jones, K. E., Patel, N. G., Levy, M. A., Storeygard, A., Balk, D., Gittleman, J. L., \& Daszak, P. (2008). Global trends in emerging infectious diseases. Nature, 451(7181), 990-993

Leavey, C., Eastaugh, A., \& Kane, M. (2020, August 30). Generation COVID-19. Building the case to protect young people's future health. The Health Foundation. Retrieved from https://www.health.org.uk/publications/long-reads/ generation-covid-19

Li, Y., Campbell, H., Kulkarni, D., Harpur, A., Nundy, M., Wang, X., \& Nair, H. (2020) The temporal association of introducing and lifting non-pharmaceutical interventions with the timevarying reproduction number (R) of SARS-CoV-2: A mod- elling study across 131 countries. The Lancet Infectious Diseases, 21(2), P193-202. Retrieved from https://doi.org/10.1016/ S1473-3099(20)30785-4

Macias, A. E., de la Torre, A., Moreni-Espinosa, S., Leal, P. E., Bourlon, M. T., \& Ruiz-Palacios, G. M. (2010). Controlling the novel A (H1N1) influenza virus: Don't touch your face! The Journal of Hospital Infection, 73(3), 280-281.

Maher, C. S., Hoang, T., \& Hindery, A. (2020). Fiscal responses to COVID-19: Evidence from local governments and nonprofits. Public Administration Review, 80(4), 644-650.

Menon, P. (2020, March 25). 'Act like you have COVID-19': PM Arden says as New Zealand heads into lockdown. Reuters World News. Retrieved from https://uk.reuters.com/article/ukhealth-coronavirus-newzealand-emergen/act-like-youhave-covid-19-pm-ardern-says-as-new-zealand-heads-intolockdown-idUKKBN21C065

Mondelli, M. U., Colaneri, M., Seminari, E. M., Baldanti, F., \& Bruno, R. (2020). Low risk of SARS-CoV-2 transmission by fomites in real-life conditions. Lancet Infectious Diseases, 21(5), E112. https://doi.org/10.1016/S1473-3099(20)30678-2.

Morawska, L., \& Milton, D. K. (2020). It is time to address airborne transmission of Coronavirus Disease 2019 (COVID-19). Clinical Infectious Diseases, 71(9), 2311-2313. Retrieved from https://doi.org/10.1093/cid/ciaa939

Mossong, J., Hens, N., Jit, M., Beutels, P., Auranen, K., Mikolajczyk, R., ... Edmunds, W. J. (2008). Social contacts and mixing patterns relevant to the spread of infectious diseases. PLoS Medicine, 5(3), e74. https://doi.org/10.1371/journal.pmed. 0050074

Nielsen, B. F., \& Sneppen, K. (2020). Superspreaders provide essential clues for mitigation of COVID-19. Preprint, MedRxiv. Retrieved from https://doi.org/10/1101/2020/09/15/20195008

Qian, H., Miao, T., Liu, L., Zheng, X., Luo, D., \& Li, Y. (2020). Indoor transmission of SARS-CoV-2. Preprint, MedRxiv. Retrieved from https://doi.org/10.1101/2020.04.04.20053058

Russell, T. W., Hellewell, J., Jarvis, C. I., Van Zandvoort, K., Abbott, S., Ratnayake, R., ... Kucharski, A. J. Estimating the infection and case fatality ratio for coronavirus disease (COVID-19) using age-adjusted data from the outbreak on the Diamond Princess cruise ship, February 2020. Eurosurveillance, 25(12). Retrieved from https://doi.org/10.2807/1560-7917. ES.2020.25.12.2000256

Sahoo, S., Jhunjhunwala, S., \& Jolly, M. K. (2020). The good, the bad and the ugly: A mathematical model investigates the differing outcomes among CoVID-19 patients. Journal of the Indian Institute for Science, Retrieved from https://doi.org/10/ 1007/s41745-020-00205-1

UK Government. (2020a). A joint statement on coronavirus (COVID-19) from the UK Government, the Northern Ireland Executive, the Scottish Government, and the Welsh Government. Cabinet Office, UK Government. Retrieved from https://www.gov.uk/government/publications/joint-statementon-covid-19/joint-statement-on-coronavirus-covid-19

UK Government. (2020b). Celebrating religious festivals during coronavirus (COVID-19). Ministry of Housing, Сommunities \& Local Government. UK Government. Retrieved from https://www.gov.uk/government/publications/covid-19guidance-for-the-safe-use-of-places- of-worship-during-thepandemic-from-4-july/celebrating-religious-festivals-duringcoronavirus-covid-19

UK Government. (2020c). Coronavirus (COVID-19): Safer travel guidance for passengers. Department for Transport. UK Government. Retrieved from https://www.gov. uk/guidance/coronavirus-covid-19-safer-travel-guidance-forpassengers

UK Government. (2020d). Stay at home: Guidance for households with possible or confirmed coronavirus (COVID-19) infection. Coronavirus (COVID-19): Safer travel guidance for passengers. Public Health England. UK Government. Retrieved from 
https://www.gov.uk/government/publications/covid-19-stay-athome-guidance/stay-at-home-guidance-for-households-withpossible-coronavirus-covid-19-infection

UK Government. (2020e). Local restriction tiers: What you need to know. Department of Health and Social Care. UK Government. Retrieved from https://www.gov.uk/guidance/localrestriction-tiers-what-you-need-to-know

UK Government. (2020f). Keeping workers and clients safe during COVID-19 in close contact services. HM Government. 5 November 2020. Retrieved from https://assets.publishing. service.gov.uk/media/5ef2889986650c12970e9b57/workingsafely-during-covid-19-close-contact-041120.pdf

University of East Anglia. (2020). UEA student facts and figs. 2019/20. Retrieved from https://www.uea.ac.uk/documents/ 37663/2822180/Facts+and+Figs.+Jan+2020.pdf/b97dfeec-5306$4490-8 \mathrm{e} 07-1 \mathrm{c} 77 \mathrm{a} 533897 \mathrm{~b} ? \mathrm{t}=1595321923736$, last updated $20 / 01 / 20$

van Doremalen, N., Bushmaker, T., Morris, D. H., Holbrook, M. G., Gamble, A., Williamson, B. N., ... Munster, V. J. (2020). Aerosol and Surface Stability of SARS-CoV-2 as Compared with SARS-CoV-1. New England Journal of Medicine, 382, 1564-1567., Retrieved from https://doi.org/10. 1056/NEJMc2004973

Wakefield, J. (2020, May 02). Coronavirus: Coping with lockdown on poor broadband. BBC News. Retrieved from https://www. bbc.co.uk/news/technology-52414280

Wikipedia. (2020). Arm span. Retrieved from https://en.wikipedia. org/wiki/Arm_span

World Bank. (2020). Global economic prospects, June 2020. Washington, DC: World Bank.

World Health Organisation. (2020a). COVID-19 Weekly Epidemiological Update. Updated 16 March 2021, available at Re- trieved from https://www.who.int/publications/m/item/weeklyepidemiological-update-on-covid-19 -6-april-2021

World Health Organisation. (2020b). Transmission of SARS-CoV2: Implications for infection prevention precautions. Scientific Brief, World Health Organisation. Retrieved from https://www. who.int/news-room/commentaries/detail/transmission-of-sarscov-2-implications-for-infection-prevention-precautions

World Health Organisation. (2020c). Coronavirus disease (COVID-19): Ventilation and air conditioning in health facilities. World Health Organisation. Retrieved from https: //www.who.int/news-room/q-a-detail/coronavirus-diseasecovid-19-ventilation-and-air-conditioning-in-health-facilities

World Health Organisation. (2020d). Advice on the use of masks in the context of COVID-19. World Health Organisation. WHO reference number: WHO/2019-nCov/IPC_Masks/2020.4. Retrieved from https://apps.who.int/iris/rest/bitstreams/1279750/ retrieve

\section{SUPPORTING INFORMATION}

Additional supporting information may be found online in the Supporting Information section at the end of the article.

Table I. Summary of the high-risk activities identified through a Hazard Analysis of Critical Control Point (HACCP) assessment for the return of students to an on-campus university setting during the COVID-19 pandemic. 